\title{
Aktivitas K.H. Sholeh Abdul Hafidz dalam Mengembangkan Dakwah Islam di Kecamatan Rancakalong Kabupaten Sumedang Tahun 1957-1987
}

\author{
Lutfa Munawar, Mahbub Hefdzil, Widiati Isana \\ Sejarah Peradaban Islam Fakultas Adab dan Humaniora, Universitas Islam \\ Negeri Sunan Gunung Djati Bandung \\ Email: lutfamunawar@gmail.com
}

\begin{abstract}
The dissemination of Islamic da'wah in the area of Rancakalong District, Sumedang Regency, began in 1957. At the time, a kiai (Islamic scholar) came from the southern Sumedang aiming to spread the Islamic da'wah in Rancakalong District. Before his arrival, The religious conditions of Rancakalong people are not so prominent. Although at that time, the mosques already existed in several places, but there was no religious leader who could guide the community yet to be able to prosper the mosque and other forms of religious activities. The was called K.H. Sholeh Abdul Hafidz. This study uses qualitative methods, namely data collection through interviews and documentation. The data analysis technique is done by the heuristic, criticism, interpretation, and historiography. The results of this study indicate that K.H. Sholeh Abdul Hafidz came to Rancakalong in 1957. The initial step of the preaching carried out by K.H. Sholeh Abdul Hafidz, began with his approach to the young and the old group of the community. The contribution form of his da'wah in Rancakalong District consisted of the establishment of the Bunsiari Islamic Boarding School I, then the Majelis Taklim of Bunsiari Islamic Boarding School I, and four Madrasa Diniyah Takmiliyah which were founded by K.H. Sholeh Abdul Hafidz'schildren.
\end{abstract}

Keywords: Islamic Da'wa, Muslim scholar, education 


\section{Pendahuluan}

Rancakalong merupakan salah satu wilayah kecamatan di Kabupaten Sumedang Provinsi Jawa Barat. Kecamatan tersebut menjadi salah satu wilayah pusat sentral budaya di Kabupaten Sumedang, yang tepatnya di Desa Rancakalong. Meskipun memiliki nama yang sama dengan nama kecamatannya, Desa Rancakalong tidak mencakup pusat pemerintahan Kecamatan Rancakalong. Sebab lokasinya yang berada di sebelah barat daya pusat kecamatan dengan jarak sekitar dua kilometer. ${ }^{1}$ Sebagian masyarakat Kecamatan Rancakalong khususnya yang berada di wilayah Desa Rancakalong memiliki sifat kearifan lokal yang secara umum terdapat pada beberapa kelompok/masyarakat minoritas atau masyarakat adat di Indonesia yang mengandung nilai luhur budaya bangsa yang masih kuat menjadi identitas warga masyarakatnya. $^{2}$

Adat istiadat yang berkembang di masyarakat Rancakalong hingga saat ini yakni kegiatan upacara adat "Ngalaksa". Ngalaksa merupakan bentuk budaya daerah yang didalamnya mengandung nilai-nilai luhur bangsa yang sangat perlu dikembangkan dalam rangka memperkuat jati diri dan kepribadian bangsa, serta menjadi pendorong program pemerintah dalam segala bidang. Pernyataan tersebut disampainkan langsung oleh Camat Rancakalong, Drs. H. Y. Karyono, M.Si. Sebelum tahun 1950-an upacara adat Ngalaksa ini sudah muncul dan lama berkembang di lingkungan masyarakat Desa Rancakalong. Dan pada tahun 1990 upacara adat ini dipusatkan disatu tempat yakni Desa Rancakalong Kecamatan Rancakalong Kabupaten Sumedang yang pelaksanaannya rutin dilaksanakan pada bulan Juli. $^{3}$

Namun seiring berkembangnya budaya tersebut, Islam pun berjalan beriringan serta berkembang di Kecamatan Rancakalong. Dan tidak bisa dipungkiri bahwa berkembangnya Islam di Kecamatan Rancakalong tidak

\footnotetext{
${ }^{1}$ http://sumedangtandang.com/direktori/detail/desa-rancakalong.htm. Diakses pada Minggu, 15 Desember 2019. Pukul 09:42.

${ }^{2}$ Guntur Cahaya Kesuma, Pendidikan Karakter Berbasis Kearifan Lokal Adat Sunda"Ngalaksa" Tarawangsa Di Rancakalong Jawa Barat (Al-Tadzkiyyah:Jurnal Pendidikan Islam, Volume 7. Dosen Fakultas dan Keguruan IAIN Raden Intan Lampung, 2016), 1

${ }^{3}$ Guntur Cahaya Kesuma, Pendidikan Karakter Berbasis Kearifan Lokal Adat Sunda"Ngalaksa" Tarawangsa Di Rancakalong Jawa Barat (Al-Tadzkiyyah:Jurnal Pendidikan Islam, Volume 7. Dosen Fakultas dan Keguruan IAIN Raden Intan Lampung, 2016), 38 .
} 
langsung diterima oleh masyarakat asli yang sudah lama menetap di wilayah tersebut. $^{4}$

Dalam berkembangnya proses penyebaran agama Islam tidak lepas dari aktivitas seorang tokoh agama atau disebut dengan Kiai. Kalau menilik sejarah, kita tahu bahwa para agamawan seperti Kiai sejak dahulu dinilai sebagai penghambat bagi kemajuan karena tidak ada kemajuan tanpa perubahan, maka mudah saja tudingan diteruskan kepada mereka sebagai pihak yang menentang perubahan. Mereka yang mengatakan agamawan tidak dapat membawa perubahan sosial beranggapan para agamawan merupakan sebuah "tradisi" yang stagnan, tidak dinamis. Objek analisis dalam studi tentang gerakan kemasyarakatan adalah pertama, individu, pusat perhatiannya yaitu kepada pada persoalan mengapa dan bagaimana individuindividu menggabungkan diri dalam sebuah gerakan-gerakan kemasyarakatan dan pada ciri-ciri khas yang membedakan individu-individu yang terlibat dalam sebuah gerakan. Kekuatan-kekuatan kultural menjadi riil dan dapat diteliti secara empiris tatkala mereka berubah bentuk kedalam motivasi, dan kecenderungan pribadi. ${ }^{5}$

Selain itu, Kiai dalam masyarakat juga berperan sebagai tokoh agama yang meliputi peran spiritual, pendidikan, agent of change, dan sosial budaya serta berperan sebagai figur yang terlibat dalam politik baik sebagai partisipan, pendukung maupun aktor. Peran spiritual Kiai bisa kita lihat di mana Kiai dipandang oleh masyarakat tradisional sebagai tokoh yang paling paham tentang agama serta apapun nasehat atau petuah dari Kiai dianggap sudah sesuai dengan syariat Islam. Peran pendidikan Kiai bisa kita lihat di mana Kiai memberikan pengajaran agama baik bagi penduduk sekitar tempat tinggalnya atau didalam lembaga pendidikan yang dia bangun. ${ }^{6}$

Jika teori-teori diatas dikaitkan dengan fakta-fakta Islam yang berkembang di Kecamatan Rancakalong dengan aktivitas dan peran seorang Kiai tentunya memiliki keterkaitan. Di antaranya aktivitas Kiai sebagai agen perubahan, sebagai figur yang paham tentang agama serta apapun nasehat atau petuah dari Kiai yang dianggap sudah sesuai dengan syariat Islam.

\footnotetext{
${ }^{4}$ H. Dadang Ahmad Harumuddin. (62 tahun), Anak Pertama K.H. Sholeh Abdul Hafidz, wawancara, Sumedang, 30 November 2019.

${ }^{5}$ Robby Darwis Nasution, Kyai Sebagai Agen Perubahan Sosial Dan Perdamaian Dalam Masyarakat Tradisional (Artikel, Volume 19 No. 2 Juli, 2017), 182.

${ }^{6}$ Nasution, Kyai Sebagai Agen Perubahan Sosial Dan Perdamaian Dalam Masyarakat Tradisional, 182.
} 
Namun di lingkungan masyarakat Indonesia, lebih condong terhadap ulama atau Kiai yang memiliki peran yang luas dan kepopuleran yang besar. Terkadang ulama dan Kiai yang memiliki ruang lingkup yang sempit atau kurang mendapat sorotan, padahal mereka memiliki kontribusi yang besar terhadap kehidupan masyarakat. Tokoh ulama atau Kiai tersebut salah satunya Kiai yang mengembangkan dakwah Islam diKecamatan Rancakalong.

Adapun tokoh agamawan atau Kiai yang mengembangkan Islam di Kecamatan Rancakalong yaitu seorang Kiai perantauan dari luar Kecamatan Rancakalong berasal dari Kecamatan Sumedang Selatan Kabupaten Sumedang yang bernama K.H. Sholeh Abdul Hafidz. Kedatangan beliau pada tahun 1957 ke wilayah Kecamatan Rancakalong memiliki tujuan, yaitu untuk mengembangkan ajaran agama Islam melalui dakwah yang dilakukannya. Yang mendasari beliau memilih wilayah Kecamatan Rancakalong sebagai tempat untuk berdakwah yaitu hasil dari istikhoroh ${ }^{7}$ guru beliau yang bernama Kiai Mama Falah Pimpinan Pondok Pesantren AlFalahiyyah Cikoneng Sumedang. Hingga K.H. Sholeh Abdul Hafidz wafat pada tahun 1985, dakwah beliau menghasilkan kontribusi dan pengaruh yang besar terhadap berkembangnya ajaran-ajaran agama Islam di Kecamatan Rancakalong hingga saat ini.

\section{A. Metode Penelitian}

Metode atau langkah-langkah yang digunakan dalam penelitian ini yaitu menggunakan metode sejarah. Adapun metode khusus yang penulis gunakan dalam penelitian ini yang mana di dalamnya berisi tahapan-tahapan sebagai berikut:

Tahapan yang pertama penulis lakukan dalam penelitian ini yaitu tahapan heuristik. Langkah ini adalah cara kerja penulis dalam memperoleh, menemukan, dan mengumpulkan sumber berikut dengan memberikan klasifikasi. Sebelum melakukan pengumpulan sumber, sejarawan perlu mengklarifikasikan bentuk sumber yang akan dikumpulkan. Penentuan sumber akan mempengaruhi tempat/di mana tempat yang bisa ditelusuri

${ }^{7}$ Istikhoroh adalah memohon kepada Allah manakahyang terbaikdari urusanyang mesti dipilih salah satunya. Lihat Rachmad Resmiyanto. Risalah Shalat Istikharah. http://rachmadresmi.blogspot.com. Diakses Pada Senin, 4 Mei 2020. Pukul 13:22. 
untuk mendapatkan sumber sejarah dan siapa atau sumber lisan yang bisa diwawancari sebagai sumber primer penelitian. ${ }^{8}$

Sumber berupa arsip:

1. Tulisan Asli K.H. Sholeh Abdul Hafidz Tentang Silsilah Nabi Muhammad S.A.W.

2. Tulisan Asli K.H. Sholeh Abdul Hafidz Tentang Amalan-amalan Tata Cara Beribadah (Fikih).

3. Tulisan Asli K.H. Sholeh Abdul Hafidz Tentang Sifat-Sifat Allah.

4. Tulisan Asli K.H. Sholeh Abdul Hafidz Tentang Adab Terhadap Orangtua

Sumber berupa dokumen:

1. Surat Pengantar CV PARITAS Jalan Pangarengan No.34 Jakarta Tahun 1982.

2. Tanda Penyetoran O.N.H Haji Bank Rakyat Indonesia Tahun 1975.

3. Teks "Chutbah Djum'ah Njambut Hari Proklamasi Kemerdekaan Ke 22.

Sumber lisan:

1. Ustadz H. Dadang Ahmad Harumudin, anak ke 1 dari K.H. Sholeh Abdul Hafidz dengan usia 63 Tahun.

2. Ustadzah Siti Nashroh, anak ke 3 dari K.H. Sholeh Abdul Hafidz dengan usia 57 Tahun.

3. Ustadzah Siti Ruqoyah, anak ke 5 dari K.H. Sholeh Abdul Hafidz dengan usia 54 Tahun.

4. Ustadz Dodo Dosen Abidarda, anak ke 8 dari K.H. Sholeh Abdul Hafidz dengan usia 51 Tahun.

5. Ustadzah Yayah Shobariyah, anak ke 9 dari K.H. Sholeh Abdul Hafidz dengan usia 48 Tahun.

6. Ustadz Yuyus Yusuf Tabriji, anak ke 10 dari K.H. Sholeh Abdul Hafidz dengan usia 45 Tahun.

7. Ustadzah Ninis Nisfusa'banah, anak ke 11 dari K.H. Sholeh Abdul Hafidz dengan usia 43 Tahun.

${ }^{8}$ Abd Rahman Hamid dan Muhammad Saleh Madjid, Pengantar Ilmu Sejarah. (Yogyakarta:Penerbit Ombak. 2014), 43. 
8. Ustadzah Een Mulyati, S.Pd., menantu K.H. Sholeh Abdul Hafidz dengan usia 55 Tahun.

9. K.H. Abdurrahman, menantu K.H. Sholeh Abdul Hafidz dengan usia 70 Tahun

10. Kiai Ahmad Sujani Jaju, menantu K.H. Sholeh Abdul Hafidz dengan usia tahun

11. K.H. Aceng Wahyudin, murid K.H. Sholeh Abdul Hafidz dengan usia 55 Tahun

12. Enceng Saka, murid pertama dari K.H. Sholeh Abdul Hafidz. dengan usia 78 Tahun.

13. Sunayat, kepala desa Cibunar periode tahun 1982 dengan usia 71 Tahun

14. Rasih, Jamah majelis ta'lim dengan usia 77 Tahun

Setelah menemukan beberapa sumber, maka langkah selanjutnya yaitu kritik. Tujuan dari langkah ini adalah menyeleksi sebuah data diubah menjadi sebuah fakta. Hal yang menjadi basis dalam dalam tahap kritik ini yaitu kehati-hatian dan rasa ragu terhadap informasi-informasi yang terdapat dalam sumber yang sudah didapatkan. Penentuan keaslian sumber yang berkaitan dengan bahan yang digunakan sumber tersebut atau dapat dikatakan sebagai kritik eksternal. Sedangkan penyeleksian yang dilakukan sejarawan terhadap informasi yang terkandung dalam sumber tersebut dapat dipercaya atau tidak, biasa disebut dengan kritik internal. Secara keseluruhan semua sumber diperlakukan sama, yaitu dilakukan penyeleksian terhadap sumber tersebut. Tahapan tersebut harus dilakukan secara sistematis dengan melakukan kritik eksternal terlebih dahulu kemudian dilakukan kritik internal. $^{9}$

Sumber Primer:

1. Tulisan Asli K.H. Sholeh Abdul Hafidz Tentang Silsilah Nabi Muhammad S.A.W., Amalan-amalan Tata Cara Beribadah (Fikih), Sifat-Sifat Allah, dan tentang Adab Terhadap Orangtua. Sumber berupa arsip ini termasuk ke dalam sumber primer karena catatan asli yang ditulis langsumg oleh K.H.Sholeh Abdul Hafidz tahun 1988.

${ }^{9}$ Hasan Usman, Metode Penelitian Sejarah, terj. Muin Umar, dkk, (Jakarta: Departemen Agama, 1992), 79-80. 
2. Surat Pengantar CV PARITAS Jalan Pangarengan No.34 Jakarta Tahun 1982, Tanda Penyetoran O.N.H Haji Bank Rakyat Indonesia Tahun 1975, Teks “Chutbah Djum'ah Njambut Hari Proklamasi Kemerdekaan Ke 22. Ketiga sumber dokumen ini penulis kategorikan ke dalam sumber primer karena masih sejaman denagn kajian yang akan diteliti oleh penulis.

Sumber Sekunder:

1. Suluk Abdul Hafidz karangan Zafar Sidiq, сиси K.H. Sholeh Abdul Hafidz ditulis pada 13 Juni 2003. Sumber ini penulis kategorikan ke dalam sumber sekunder karena sumber ini ditulis oleh cucu K.H. Sholeh Abdul Hafidz.

Tahapan interpretasi yaitu kegiatan merangkaikan fakta-fakta yang sudah didapat itu menjadi suatu keseluruhan yang masuk akal. ${ }^{10}$ Kemampuan dalam langkah interpretasi yaitu dengan menguraikan fakta-fakta sejarah serta kepentingan tema atau topik sejarah dan menjelaskan masalah secara kekinian. $^{11}$

Konsep tindakan sosial dan otoritas kepemimpinan, penulis gunakan kedua konsep sebagai konsep untuk menganalisis Aktivitas K.H. Sholeh Abdul Hafidz Dalam Mengembangkan Dakwah Islam di Kecamatan Rancakalong Kabupaten Sumedang Tahun 1957-1987. Konsep tersebut merujuk kepada dasar pertimbangan bahwa keberadaan berkembangnya agama Islam serta ajaran-ajarannya di wilayah Kecamatan Rancakalong Kabupaten Sumedang tidak bisa dipisahkan oleh suatu tindakan serta tipe kepemimpinan yang dilakukan oleh K.H Sholeh Abdul Hafidz sebagai tokoh sentral pada kurun waktu dari tahun 1957-1987. K.H. Sholeh Abdul Hafidz merupakan Kiai yang memiliki tujuan utama yaitu mengembangkan dakwah Islam, mengamalkan ilmu-ilmu yang telah didapatkan dari guru-guru beliau melalui dakwah yang disampaikan kepada masyarakat. Dengan demikian, tempat yang bertempat di Kecamatan Rancakalong, masyarakat, dan pesantren yang didirikan beliau menjadi alat dan sarana untuk mencapai tujuan tersebut. Itulah berupa tindakan sosial rasional yang ditunjukkan K.H. 2012), 30 .

${ }^{10}$ Drs. Aam Abdillah, M.Ag, Pengantar Ilmu Sejarah, (Bandug:CV Pustaka Setia,

${ }^{11}$ Dr.H. Sulasman, M.Hum, Metodologi Penelitian Sejarah, (Bandung:CV Pustaka Setia, 2014), 109. 
Sholeh Abdul Hafidz dalam kaitannya dengan usaha menyebarkan agama Islam di kalangan Masyarakat Rancakalong.

Historiografi merupakan tahapan puncak dari segala-galanya dalam metode penelitian sejarah. Dalam fase ini sejarawan mengungkapkan, menangkap sekaligus memahami historie ralite atau sejarah sebagaimana terjadinya. Langkah awal dalam tahapan historiografi yaitu pertama melakukan seleksi, kemudian kronologi dan imajinasi. Seleksi merupakan tahapan sejarawan dalam menyeleksi bukti yang relevan dan tidak relevan dan memisahkan bukti-bukti yang berkaitan atau tidak. Kemudian tahap kronologi adalah pembatasan waktu atau limit waktu. Tahapan ini dilakukan agar sejarawan fokus terhadap satu masa waktu yang akan diteliti, sehingga tidak terjadi penyelewangan tempat dan waktu. Dilanjutkan dengan tahapan imajinasi yang berkaitan dengan khalayan seorang sejarawan dalm melakukan peristiwa tetapi dibatasi dengan fakta-fakta, tidak berimajinasi sembarangan atau menuliskan secara bebas seperti halnya seorang sejarawan. $^{12}$.

\section{Hasil dan Pembahasan}

\section{Biografi K.H. Sholeh Abdul Hafidz}

\section{Riwayat Keluarga K.H.Sholeh Abdul Hafidz}

K.H. Sholeh Abdul Hafidz atau sering dipanggil dengan Aki Aleh, beliau adalah seorang tokoh agama yang mengembangkan dakwah Islam di wilayah Kecamatan Rancakalong Kabupaten Sumedang. Beliau dilahirkan di Kampung Salambitan Desa Cigembong Kecamatan Sumedang Selatan pada hari Kamis tanggal 10 Shofar tahun 1345 Hijriyah atau bertepatan pada tahun 1927. ${ }^{13}$ K.H. Sholeh Abdul Hafidz merupakan anak keenam dari pasangan Eyang Angga Praja yang lahir tahun 1881 dan wafat tahun 1939 dan Emeh Salamah yang lahir tahun 1888 dan wafat tahun 1961. K.H. Sholeh Abdul Hafidz terlahir dari sembilan bersaudara yang terdiri dari lima kakak, yaitu Sambas Damiri Abdul Ghofur, Andan Mahfuddin, Atang Abdul

\footnotetext{
${ }^{12}$ Louis Gottschalk, Mengerti Sejarah (Jakarta : UI-Press, 2015), 41.

${ }^{13}$ H.Dadang Ahmad Harumuddin.(62 tahun), Anak Pertama K.H. Sholeh Abdul Hafidz, wawancara, Sumedang, 30 November 2019.
} 
Aziz, Sarnasih Haqiah, dan O. Qomariah, dan mempunyai adik, yaitu Uwar Warsi'ah, JK Saefuddin, Adam Alan Dahlan Ahmad Marjuki. ${ }^{14}$

Latar belakang keluarga Eyang Angga Praja dan Uyut Emeh Salamah keduanya memiliki darah ningrat. Sehingga nama Eyang Angga Praja diabadikan ke dalam salah satu sebuah nama jalan di Sumedang Selatan yaitu Jl.Angga Praja. Terlihat dari silsilahnya bahwa Uyut Emeh Salamah adalah silsilah ke delapan dari Raden Angkawijaya atau Prabu Geusan Ulun ${ }^{15}$ bin Raden Kusumadinata yang dijuluki dengan Pangeran Santri ${ }^{16}$. Silsilah Uyut Emeh Salamah juga bersambung dengan silsilah keturunan K.H. Sholeh Abdul Hafidz dari keturunan ke 12 dari atas yaitu Nyimas Ratu Petak yang menyambung ke Syekh Syarif Hidayatullah atau Sunan Gunung Djati. ${ }^{17}$ Dengan demikian, secara genealogis ${ }^{18}$ K.H. Sholeh Abdul Hafidz terlahir dari keturunan yang berasal dari kalangan Ulama ${ }^{19}$ dan Kiai $^{20}$.

\section{${ }^{14}$ Zafar Shidiq.2013. Suluk Abdul Hafidz..Rancaekek:Bandung}

${ }^{15}$ Prabu Geusan Ulun adalah putra pertama dari Pangeran Santri. Lihat Euis Thresnawaty S. 2011. Sejarah Kerajaan Sumedang Larang. Balai Pelestarian Sejarah dan Nilai Tradisional Bandung Jln.Cinambo No. 136 Ujungberung Bandung.patanjala Vol. 3, No. 1, Maret 2011: 154-168. hlm. 161.

${ }^{16}$ Pangeran santri adalah cucu Sunan Gunung Djati menurut garis ibu. Pangeran Santri diperkirakan wafat pada tahun 1578, dimakamkan di Gunung Ciung, Kota Sumedang. Pangeran Santri juga adalah bupati pertama yanh menganut Islam dan membangun Kutamaya sebagai ibukota baru dan menjadi pusat pemerintahan. Lihat Euis Thresnawaty S. ; Sejarah Kerajaan Sumedang Larang (Balai Pelestarian Sejarah dan Nilai Tradisional Bandung Jln.Cinambo No. 136 Ujungberung Bandung.patanjala Vol. 3, No. 1, Maret 2011), 154-168.

${ }^{17}$ Zafar Shidiq, Suluk Abdul Hafidz (Rancaekek:Bandung, 2013)

${ }^{18}$ Genealogis : Garis keturunan manusia dalam keluarga sedarah. (http://kbbi.web.id/genealogi)

${ }^{19}$ Ulama dapat diartikan sebagai seseorang yang berada dalam posisi di bidang keagamaan menjadi fungsionaris keagamaan atau pejabat. Lihat Setia Gumilar.2013..hlm.71.

${ }^{20}$ 'Kyai' diartikan sebagai penyebutan kepada seseorang yang dihormati yang memiliki ilmu keagamaan. Secara luas, terdapat beberapa penafsirannya. Dalam percakapan di beberapa daerah, 'ajengan' memiliki arti sinonim dengan 'kiai'. Kiai sebagai aktor sosial yang lekat dengan aspek agama, pada per- kembangannya dapat memunculkan diri sebagai kiai itu sendiri, dan atau seorang agamawan. Konsep pertama biasanya digunakan dalam kajian yang lebih netral dalam melihat ketokohan dan aktivitas kiai terhadap umatnya, yaitu cara seorang kiai melakukan dakwah, cara dan metode, dan beberapa kajian mengenai kekua- tan pengaruh kiai terhadap lingkungannya. Lihat Sayfa Aulia Achidsti, Kebudayaan Islam: Eksistensi dalam Masyarakat. Vol.12,No.2,Juli-Desember. (Yogyakartah:Universitas Gadjah Mada. 2014) 1-2. Kyai adalah seseorang yang menjadi salah satu elemen paling utama di suatu lingkungan pesantren, bahkan ia-lah yang menjadi pendirinya. Dengan demikian sudah sepantasnya pertumbuhan dan berkembangnya suatu pesantren semata-mata tergantung dengan sifat dan pribadi kyainya. Dari asl-usulnya kyai digunakan untuk tiga 


\section{Riwayat Pendidikan K.H. Sholeh Abdul Hafidz}

Seperti anak-anak pada umumnya beliau mengawali jenjang pendidikan nya di Sekolah Desa di Cikondang Selambitan Kecamatan Sumedang Selatan dari tahun 1935 dan lulus tahun 1938. Sekolah Desa atau Sekolah Rakyat yang setara dengan Sekolah Dasar pada zaman sekarang. Setelah lulus dari Sekolah Desa beliau melanjutkan pendidikannya di Sekolah Shakel yang berada di Cikalong dari tahun 1938 sampai 1939. Setelah satu tahun di Sekolah Shakel dan lulus tahun 1939, beliau memulai pendidikan di Pesantren. Pesantren Cipancar menjadi pesantren pertama yang beliau singgahi untuk mencari ilmu agama. Pesantren yang dipimpin oleh Ajengan Hajar ini, K.H. Sholeh Abdul Hafidz menimba ilmu selama tahun dari tahun 1939 sampai $1941 .^{21}$

Tidak sampai disitu, beliau melanjutkan menjadi santri ${ }^{22}$ di Pondok Pesantren Al-Falahiyyah Cikoneng Kecamatan Ganeas Kabupaten Sumedang yang pimpinannya adalah Ajengan Mama Falah. Pesantren ini dijadikan oleh K.H. Sholeh Abdul Hafidz sebagai sarana untuk mendidik anak-anaknya. Beliau memasukkan sebagian anaknya ke pesantren ini. Saat beliau masih berada di jenjang pendidikan pesantren, beliau tidak hanya belajar dan mengaji saja, tetapi beliau juga sering diajak oleh gurunya untuk berjuang di luar lingkungan pesantren. Beliau sering diajak oleh Kiai Mama Falah untuk ikut berjuang, bahkan beliau pernah menjadi tahanan politik selama berjuang mengikuti gurunya itu. Sehingga K.H. Sholeh Abdul Hafidz dikenal juga sebagai Kiai yang mempunyai rasa nasionalisme yang tinggi,

gelar yang memiliki arti berbeda satu sama lain, yaitu: 1. Kyai sebagai gelar yang digunakan untuk benda-benda atau barang-barang yang dianggap keramat ataupun sakti. 2. Kyai sebagai gelar yang diberikan kepada orang-orangyang sudah lanjut usia atauorang tua secara umum. 3. Kyai sebagai gelar yang gunakan masyarakat untukdiberikan kepada seorang yang mempunyai ilmu agama yang kental dengan pesantren yang didirikannya dan mengamalkan ilmunya dengan mengajarkan kitab-kitab Islam klasik atau kitab kuning kepada santrinya. Lihat Zamakhsyari Dhofier, Tradisi Pesantren:Studi Pandangan Hidup Kyai dan Visinya Mengenai Masa Depan Indonesia ( Jakarta:LP3ES,2019), 93.

${ }^{21}$ Zafar Shidiq, Suluk Abdul Hafidz (Rancaekek:Bandung, 2013)

${ }^{22}$ Santri secara umum adalah sebuatan bagi seseorang yang mengikuti pendidikan agama Islam di pesantren, biasanya menetapdi tempattersebuthingga pendidikannya selesai. Menurut bahasa istilah snatri berasal dari bahasa Sangsekerta, "shastri" yang memiliki akar kata yang sama dengan katasastra yang berartikitab suci,agama,dan pengetahuan. Ada pula yang mengatakanberasaldari kata cantrik yang berarti pembantu begawan.seorang cantrik diberi upah berupa ilmu pengetahuan oleh begawan atau resi tersebut. Tidak jauh beda dengan seorang santri yang mengabdidi pesantren, sebagai konsekuensinya ketua pondokpesantren memberikan tunjangan kepada santri tersebut. Lihat http://.m.wikipedia.org/wiki/Santri. Diakses Pada Sabtu, 8 Februari 2020 Pukul 19:03. 
bukan hanya agama yang diperjuangkan tetapi memperjuangkan dan mempertahankan keutuhan NKRI (Negara Kesatuan Republik Indonesia) pun beliau lakukan. ${ }^{23}$

\section{Catatan Asli K.H.Sholeh Abdul Hafidz}

1) Catatan Asli K.H. Sholeh Abdul Hafidz Tentang Silsilah Nabi Muhammad S.A.W Tahun 1988

2) Catatan Asli K.H. Sholeh Abdul Hafidz Tentang Tata Cara Beribadah (Fikih) dan Tajwid

3) Catatan Asli K.H. Sholeh Abdul Hafidz Tentang Tauhid Tahun 1988

4) Catatan Asli K.H. Sholeh Abdul Hafidz Tentang Adab Terhadap Orangtua Tahun 1988

\section{Aktivitas Dan Kontribusi K.H. Sholeh Abdul Hafidz Dalam Mengembangkan Dakwah Islam Di Kecamatan Rancakalong Kabupaten Sumedang Tahun 1957-1987}

\section{Kondisi Sosial Keagamaan Masyarakat Rancakalong Sebelum Kedatangan K.H. Sholeh Abdul Hafidz}

Kondisi keagamaan di Kecamatan Rancakalong pada tahun 1957 belum begitu berkembang. Meskipun di setiap wilayah di Rancakalong sudah berdiri beberapa masjid kecil tetapi tidak ada kegiatan shalat berjamaah, kegiatan pengajian ataupun majelis taklim. Masyarakat pada saat itu hanya mengetahui dirinya memilki agama yaitu agama Islam, tetapi masyarakat belum mengetahui inti dari ajaran agama Islam itu sendiri. ${ }^{24}$ Berikut beberapa alasan yang menjadi timbulnya hal tersebut yaitu sebagai berikut:

1) Tahun 1957-an di Kecamatan Rancakalong belum hadir seorang pemuka agama yang bisa menuntun masyarakatnya kepada ajaran Islam yang baik dan benar.

\footnotetext{
${ }^{23}$ Dodo Abidarda.(51 tahun), Anak Kelima K.H. Sholeh Abdul Hafidz, Wawancara, Sumedang, 20 Januari 2020.

${ }^{24}$ Mohammad Hasby Assidik, Peran KH. Muhammad Sudja'i Dalam Dakwah Islam Di Desa Cileunyi Wetan Kecamatan Cileunyi Kabupaten Bandung Tahun 1931-1983. (Bandung: Jurusan Sejarah dan Peradaban Islam Fakultas Adab dan Humaniora Universitas Islam Negeri Sunan Gunung Djati Bandung, 2012), 28.
} 
2) Hampir seluruh masyarakat Rancakalong pada saat itu masih berpegang teguh dengan ajaran nenek moyang melalui budaya Ngalaksa yang sudah lama hadir di wilayah tersebut.

3) Kepercayaan animisme menjadi kepercayaan yang mendominasi pada saat itu.

4) Kegiatan keagamaan belum terlihat karena dilema yang alami oleh masyarakat Sumedang karena kehadiran DI/TII ${ }^{25}$ pada tahun 19501962.

Bahkan lembaga-lembaga keagamaan pun belum berdiri seperti sekarang, karena tidak adanya seorang pelopor atau orang yang memprakarsai berdirinya lembaga keagamaan tersebut. Sebelum kedatangan K.H. Sholeh Abdul Hafidz kegiatan majelis taklim belum berdiri sama sekali. Begitu pun kegiatan pengajian seperti Taman Pendidikan Al-Qur'an, Madrasah Diniyah, bahkan pesantren pun belum ada di wilayah ini. ${ }^{26}$

Dari uraian tersebut dapat disimpulkan bahwa kondisi sosial keagamaan masyarakat Kecamatan Rancakalong sebelum kedatangan K.H. Sholeh Abdul Hafidz belum begitu signifikan terlihat. Meskipun pada saat itu masjid-masjid sudah berdiri dibeberapa tempat, tetapi belum hadir seorang pemuka agama yang bisa menuntun masyarakat untuk bisa memakmurkan masjid dan bentuk kegiatan keagamaan lainnnya.

\section{Kondisi Sosial Kebudayaan Masyarakat Rancakalong Sebelum Kedatangan K.H. Sholeh Abdul Hafidz}

Menurut kesaksian salah satu anak K.H. Sholeh Abdul Hafidz keadaan sosial kebudayaan masyarakat Rancakalong sebelum K.H. Sholeh Abdul Hafidz datang, bisa dikatakan masyarakatnya kebanyakan masih

\footnotetext{
${ }^{25}$ DI/TII adalah singakatan dari Darul Islam Tentara Islam Indonesia yang merupakan gerakan politik yang memiliki kerangka berfikir hasil Kartosoewirjo. Darul Islamadalah sebuah bentuk masyarakat yang tertib dan berlandaskan kepada ajaran Islam. Gerakan politik disini yang dimaksud bukan gerakan yang mengarah terhadap partai politik tepi gerakan yang berawal darisebuah keyakinan terhadap nilai atau ideologi dan berdasar kepada kesamaan itu berusaha menjadikan nilai tau ideology tersebut diakui oleh semua orang itu benar yang meliputi hukum Islam. Lihat Wahyu Irwansyah Tambunan.. Gerakan Politik S.M. Kartosoewirjo (DI?TII 1949-1962). Jurnal POLITEIA, Vol 6. No.1 (Medan: Departemen Ilmu Politik Fakultas Ilmu Sosial dan Ilmu Politik Universitas Sumatera Utara 2014), 33. Diakses Pada Jum'at, 1 Mei 2020 Pukul 14:00.

${ }^{26}$ Een Mulyati. (55 tahun), Menantu K.H. Sholeh Abdul Hafidz, Wawancara, Sumedang, 30 November 2019.
} 
mempercayai kepercayaan Animisme ${ }^{27}$. Kepercayaan Animisme ini bersumbu pada tradisi Ngalaksa atau Tarawangsa yang sangat kuat dijalankan oleh masyarakat, bahkan terdapat tokoh yang menjadi panutan masyarakat pada saat itu yang bernama Wirya Dinata. ${ }^{28}$

Tetapi tradisi Tarawangsa memiliki pandangan bahwa agama yang mereka anut agama yang dari nenek moyang atau yang sering disebut dengan karuhun. Budaya tersebut sampai sekarang masih dilestarikan yang diteruskan oleh penerus Wirya Dinata. Bahkan budaya tersebut semakin dikenal banyak orang, dan rutin dilaksanakan oleh masyarakat Rancakalong. Karena dilihat dari sisi kebudayaan, Tarawangsa ini hanya terdapat satu di Indonesia bahkan dunia. Sehingga pemerintah mendukung dan mempertahankan keberadaannya. Namun pandangan bahwa budaya ini menjadi sumbu kepercayaan utama dalam beragama berubah semenjak kedatangan K.H. Sholeh Abdul Hafidz ke Rancakalong untuk berdakwah.

\section{Aktivitas K.H. Sholeh Abdul Hafidz dalam Mengembangkan Dakwah Islam di Kecamatan Rancakalong Tahun 1957-1987}

\section{Kedatangan K.H. Sholeh Abdul Hafidz ke Rancakalong}

Awal kedatangan K.H. Sholeh Abdul Hafidz ke Rancakalong pada tahun 1957 dilatarbelakangi dengan kondisi keagamaan Sumedang terutama di Kampung Sulambitan Sumedang Selatan pada saat itu yang sedang gencar-gencarnya DI/TII, K.H. Sholeh berada dalam kondisi yang tidak aman pada saat itu karena terdapat dugaan bahwa beliau bagian dari DI/TII. Diriwayatkan ketika kondisi saat itu sedang tidak aman, di Kampung Sulambitan ada seorang pendatang dari Rancakalong yang bernama Bapak Ece. Dia merupakan warga asli Cibunar Kecamatan Rancakalong yang akhirnya mengajak K.H. Sholeh Abdul Hafidz ke Rancakalong agar K.H. Sholeh Abdul Hafidz berada dalam kondisi yang aman. Kemudian beranjaklah K.H. Sholeh Abdul Hafidz dengan bapak Ece ke Rancakalong tepat pada tahun $1957 .^{29}$

${ }^{27}$ Animisme adalah kepercayaan kepada makhluk halus dan roh merupakan asas kepercayaan agama yang mula-mula muncul dikalangan manusia primitive. http://id.m.wikipedia.org/wiki/Animisme. Diakses Pada Rabu, 13 Mei 2020. Pukul 10:25.

${ }^{28}$ H.Dadang Ahmad Harumuddin. (62 tahun), Anak Pertama K.H. Sholeh Abdul Hafidz, wawancara, Sumedang, 30 November 2019.

${ }^{29}$ Enceng Saka, (78 tahun), murid pertama K.H. Sholeh Abdul hafidz, Wawancara, Sumedang, 27 April 2020. Pukul 10:30. 
Selain karena ajakan dari Bapak Ece untuk pergi ke Kecamatan Rancakalong, keputusan tersebut secara kebetulan sesuai dengan hasil istikhoroh yang dilakukan oleh guru dari K.H. Sholeh Abdul Hafidz yaitu Kiai Haji Mama Falah Pengasuh Pondok Pesantren Al Falahiyyah Cikoneng Sumedang, beliau memberikan dua tempat pilihan yang dijadikan sebagai singgahan untuk mengembara dan mengamalkan ilmu yang dimiliki oleh K.H. Sholeh Abdul Hafidz. Dua tempat yang menjadi pilihan tersebut yaitu dua kecamatan yang ada di Kabupaten Sumedang yaitu Kecamatan Buahdua dan Kecamatan Rancakalong. Dan akhirnya Rancakalong menjadi pilihan K.H. Sholeh Abdul Hafidz untuk memperjuangkan agama Allah SWT. ${ }^{30}$

Setelah beliau sampai di Rancakalong, K.H. Sholeh Abdul Hafidz berdiam di kediaman Bapak Ece di Dusun Cibunar Desa Cibunar Kecamatan Rancakalong. beserta istrinya yaitu Ibu Uwet yang sudah memiliki satu anak yang bernama Sunayat. Dari tempat inilah beliau memulai dakwahnya. Dengan dukungan yang diberikan oleh keluarga bapak Ece, K.H. Sholeh Abdul Hafidz melakukan dakwahnya dengan melakukan pendekatan perlahan kepada warga lokal setempat. Selama K.H. Sholeh Abdul Hafidz tinggal di rumah tersebut beliau mengawali langkah dakwahnya tidak langsung memperlihatkan seorang pendakwah, penyebar ajaran agama Islam, ataupun seorang yang mempunyai ilmu agama, sehingga saat melaksanakan shalat pun dilakukan secara diam-diam bahkan beliau tidak pernah memakai peci sama sekali agar masyarakat tidak menaruh curiga kepada beliau. ${ }^{31}$ Beliau menunjukkan dirinya seperti masyarakat setempat pada umumnya dengan membuka usaha jahit di kediaman Bapak Ece dengan nama usaha menjahit Al-Ikhlas. ${ }^{32}$

\section{Proses Dakwah K.H. Sholeh Abdul Hafidz}

Langkah awal dakwah yang dilakukan oleh K.H. Sholeh Abdul Hafidz diawali dengan pertemuan dengan seorang remaja yang bernama Enceng Saca di desa Cibunar Kecamatan Rancakalong. Diriwayatkan pada

\footnotetext{
${ }^{30}$ K.H. Abdurrahman.( 70 tahun), menantu dari anak ke tiga K.H. Sholeh Abdul Hafidz, Wawancara, Sumedang 7 Februari 2020. Pukul 16:30 WIB.

${ }^{31}$ Dodo Abidarda. (51 tahun), Anak Kelima K.H. Sholeh Abdul Hafidz, Wawancara, Sumedang, 20 Januari 2020. Pukul 16:30 WIB.

${ }^{32}$ Enceng Saka, (78 tahun), murid pertama K.H. Sholeh Abdul hafidz, Wawancara, Sumedang, 27 April 2020. Pukul 10:30.
} 
saat waktu sudah adzan dhuhur K.H. Sholeh Abdul Hafidz akan melaksanakan shalat dhuhur di salah satu masjid kecil yang berada diwilayah tersebut, tepatnya di masjid Ciduriat. Sesaat sebelum masuk masjid tersebut K.H. Sholeh Abdul Hafidz bertemu dengan seorang remaja yang sedang mencari rumput disekitaran masjid. Kemudian K.H. Sholeh Abdul Hafidz menghampirinya dan bertanya tentang keberadaan kegiatan pengajian di daergh tersebut. Enceng Saca mengungkapkan bahwa disini belum ada kegiatan pengajian seperti majelis taklim, pengajian alqur'an dan lain sebagainya. Dikarenakan di wilayah Rancakalong ini khususnya di desa Cibunar kondisi sosial keagamaan Islamnya sangat kurang dan masyarakatnya pun belum memilki seorang pemuka agama yang bisa menuntun mereka dalam menganut ajaran Islam. Setelah mengetahui keterangan tersebut K.H. Sholeh Abdul Hafidz beranjak shalat dhuhur dengan tanpa memakai peci dan sarung. Remaja yang bernama Enceng Saca tadi langsung melanjutkan kegiatan mencari rumputna. Itu merupakan salah satu pertemuan pertama K.H. Sholeh Abdul Hafidz dengan warga lokal semenjak datang di wilayah Rancakalong tahun 1957.

Diriwayatkan bahwa pertemuan tersebut adalah salah satu dari sekian pertemuan K.H. Sholeh Abdul Hafidz yang dilakukan oleh beliau dengan warga lokal dalam rangka pendekatan secara perlahan untuk mengajak warga-warga di wilayah tersebut ikut mengaji dengan beliau. Sehingga tidak butuh waktu lama K.H. Sholeh Abdul Hafidz memiliki beberapa murid dari golongan muda yaitu Enceng Saca, Atak, Kata, Iyed, dan Takrim. Mereka adalah lima remaja yang menjadi murid K.H. Sholeh Abdul Hafidz yang rutin melakukan pengajian setiap ba'da maghrib hingga adzan Isya yang bertempat di masjid Ciduriat.

Dari hari ke hari pengikut K.H. Sholeh Abdul Hafidz semakin bertambah. Hal yang dilakukan oleh beliau untuk menarik perhatian warga lokal yaitu dengan sistem "Jemput Bola” dengan mengunjugi masjid-masjid yang berada di desa Cibunar. Desa Cibunar menjadi wilayah yang menjadi basis pengembangan dakwah yang dilakukan oleh beliau, selain karena desa Cibunar menjadi tempat pertama yang beliau singgahi, keinginan beliau agar warga yang berada di wilayah tersebut menjadi prioritas utama menerima dakwah beliau. Golongan muda pun semakin bertambah yang mengikuti kegiatan pengajian beliau, namun tidak hanya dari golongan muda, dari 
golongan tua pun sudah ada yang bersedia menjadi pengikut beliau walaupun jumlahnya kalah dari golongan muda. ${ }^{33}$

Selama setahun lamanya pengajian tersebut berjalan. Namun dari segi perkembangannya tidak begitu pesat karena kendala tempat permanen yang belum dimiliki oleh K.H. Sholeh Abdul Hafidz, sehingga waktu mengaji pun tidak begitu efektif pada saat itu karena tempat yang terlalu kecil sehingga tidak bisa menampung murid-murid beliau. Dalam perintisan selama satu tahun itu, K.H. Sholeh Abdul Hafidz sudah mulai berkunjung ke masjid-masjid yang lokasi di luar desa Cibunar seperti Kampung Pangkalan dan Kampung Cibeurih yang berlokasi di Desa Nagarawangi, kemudian Kampung Babakadago, dan Desa Kayang juga beliau kunjungi dengan berjalan kaki. Dengan demikian, murid muridnya pun semakin bertambah banyak. $^{34}$

Sebuah proses dakwah pasti memiliki hambatan dan tantangan. Termasuk dakwah yang dialami oleh K.H. Sholeh Abdul Hafidz. Salah satunya yaitu terdapat sebagaian masyarakat Rancakalong yang beranggapan bahwa K.H. Sholeh Abdul Hafidz bagian dari DI/TII. Karena pada tahun tahun itu, warga Sumedang mengalami dilemma atas kehadiran DI/TII sekitaran tahun 50an. Selama proses dakwah yang beliau lakukan, K.H.Sholeh Abdul Hafidz selalu ditemani oleh salah satu muridnya yaitu Enceng Saca kemanapun beliau pergi. Baik saat beliau bertemu dengan orang-orang penting, dan juga saat pergi dari desa ke desa untuk mengisi pengajian-pengajian. ${ }^{35}$

\section{Pola Dakwah K.H. Sholeh Abdul Hafidz}

\section{a) Metode Bil Hikmah}

Metode tersebut dilakukan oleh K.H. Sholeh Abdul Hafidz ketika awal masuk ke wilayah Rancakalong. sebelum beliau menyampaikan dakwahnya, terlebih dahulu beliau melihat kondisi masyarakat Rancakalong dengan melakukan silaturahmi dengan masyarakat baik dari golongan muda ataupun

\footnotetext{
${ }^{33}$ Enceng Saka, (78 tahun), Murid pertama K.H. Sholeh Abdul Hafidz, Wawancara, Sumedang, 27 April 2020. Pukul 10:30

${ }^{34}$ Enceng Saka, (78 tahun), Murid pertama K.H. Sholeh Abdul Hafidz, Wawancara, Sumedang, 27 April 2020. Pukul 10:30.

${ }^{35}$ Enceng Saka, (78 tahun), Murid pertama K.H. Sholeh Abdul Hafidz, Wawancara, Sumedang, 27 April 2020. Pukul 10:30
} 
golongan tua. Melihat kondisi masyarakat Rancakalong yang belum mengetahui ajaran agama Islam yang baik dan benar karena belum tersedianya pemuka agama, beliau menyampaikan ilmu-ilmu dasar agama Islam kepada masyarakat. Golongan muda menjadi golongan masyarakat yang banyak ikut dalam pengajian-pengajian beliau. Ilmu yang beliau sampaikan antara lain seperti ilmu tauhid kepada Allah dan Rosul-Nya yang dikemas dengan berupa nadhoman sehingga masyarakatnya pun bisa mudah hafal, paham kemudian diamalkan. Metode ini digunakan hingga beliau bisa mendirikan majelis taklim dan Pondok Pesantren Bunisari. ${ }^{36}$

b) Metode al-Mau'izhatul Hasanah

K.H. Sholeh Abdul Hafidz menggunakan metode ini dalam perjalanan dakwahnya. Metode ini digunakan ketika beliau sudah memiliki anak dari istrin yaitu Ny. Icih Masitoh. Dalam lingkungan keluarga, K.H. Sholeh Abdul Hafidz selain menjadi kepala keluarga, beliau juga merupakan sosok yang dijadikan anak-anaknya serta menantunnya sebagai suri tauladan dalam hal mendidik dan menasihati orang-orang yang berada di lingkungan keluarganya. Kesederhanaan menjadi sifat utama beliau dalam mendidik sembilan anaknya. Selain itu suri tauladan yang dijadikan contoh oleh anak dan menantunya yaitu sifat beliau yang tidak pernah menyuruh atau memerintah kepada anak-anaknya tetapi beliau mengerjakan suatu hal positif terlebih dahulu hingga anak-anaknya melihat kemudian mengikuti sehingga tertanamlah rasa mandiri dan kesadaran semenjak kecil, hal tersebut diterapkan kepada anak-anak beliau dalam rangka mendidik anak. ${ }^{37}$

\section{c) Metode Jadilhum Billati Hiya Ahsan}

Metode dakwah ini dilakukan oleh K.H. Sholeh Abdul Hafidz ketika beliau sudah memiliki Pondok Pesantren Bunisari dan jumlah santri yang cukup banyak. Beliau mengadakan sebuah forum diskusi baik dengan santri ataupun masyarakat dalam memecahkan permasalahan yang berkaitan dengan ajaran agama. Beliau mempersilahkan kepada santri dan masyarakat untuk mengutarakan hal-hal masalah yang perlu didiskusikan. ${ }^{38}$

\footnotetext{
${ }^{36}$ Enceng Saka, (78 tahun), murid pertama K.H. Sholeh Abdul hafidz, Wawancara, Sumedang, 27 April 2020. Pukul 10:30

${ }^{37}$ Een Mulyati. (55 tahun), Menantu K.H. Sholeh Abdul Hafidz, Wawancara, Sumedang, 26 April 2020.

${ }^{38}$ K. Ahmad Sujani Jaju. (66 tahun), Menantu dari anak keempat K.H. Sholeh .Abdul Hafidz, Wawancara, Sumedang, 17 Januari 2020.Pukul 13:00.
} 
Kemudian K.H. Sholeh Abdul Hafidz memeberikan solusi tepat dengan merujuk kitab-kitab yang sudah dipegang sebagai rujukan kuat dalam menguatkan keilmuannya. Menurut pernyataan Kiai Ahmad Sujani Jaju selaku penerus pimpinan Pondok Pesantren Bunisari I menyatakan bahwa beliau masih menggunakan metode tersebut hingga sekarang. Dengan membuka forum diskusi alumni-alumni pesantren untuk menyampaikan danmendiskusikan permasalahan yang ada di lingkungan masyaraktnya masing-masing khususnya di wilayah kecamatan Rancakalong. ${ }^{39}$

\section{Kontribusi Aktivitas K.H. Sholeh dalam Mengembangkan Dakwah K.H.Sholeh Abdul Hafidz di Kecamatan Rancakalong Tahun 1957-1987}

Kontribusi dari aktivitas K.H. Sholeh Abdul Hafidz dalam mengembangkan dakwah Islam di Kecamatan Rancakalong pada tahun 1957 masih berjalan hingga sekarang. Perjuangan beliau dilanjutkan oleh anakanak serta menantu-menantu beliau, tidak terkecuali dengan murid-murid beliau. Bentuk kontribusi yang masih terlihat hingga sekarang adalah berdirinya lembaga-lembaga keagamaan di Kecamatan Rancakalong setelah beliau datang, terdiri dari:

1) Pondok Pesantren Bunisari I yang berdiri tahun 1970-an yang dipimpin oleh K. Sujani Jaju (Menantu K.H. Sholeh Abdul Hafidz), Pondok Pesantren Bunisari II yang berdiri yang dipimpin oleh K.H. Abdurrahman (Menantu K.H. Sholeh Abdul Hafidz). Kemudian dari orang yang menjadi santri K.H. Sholeh Abdul Hafidz mendirikan juga Pondok Pesantren Al-Huda dipimpin oleh K.H. Aceng Wahyudin, dan Pondok Pesanten Al Ulumusyariah yang dipimpin oleh Ustadz Muhammad Nurbih.

2) Selain lembaga pesantren yang berdiri hingga sekarang, majelis taklim menjadi salah satu kontribusi yang berkembang pesat dan menyebar di wilayah sekecamatan Rancakalong. Selain Majelis Taklim yang dilaksanakan Mingguan di Pondok Pesantren Bunisari I ada sekitar puluhan majelis taklim di kecamatan Rancakalong yang hampirseluruhnya dikelola oleh keluarga K.H. Sholeh Abdul Hafidz dan alumni Pondok Pesantren Bunisari I.

${ }^{39}$ Kyai Ahmad Sujani Jaju. (66 tahun), Menantu dari anak keempat K.H. Sholeh .Abdul Hafidz, Wawancara, Sumedang, 17 Januari 2020. Pukul 13:00 WIB. 
3) Dan yang terakhir adalah Madrasah Diniyah Takmiliyah sebagai kontribusi dakwah K.H. Sholeh Abdul Hafidz yang diteruskan oleh anak-anak beliau. Terdapat lima Madrasah Diniyah Takmiliyah yang ditiap desa di kecamatan Rancakalong bahkan ada yang di luar kecamatan sekalipun. Lima Madrasah Diniyah Takmiliyah tersebut menjadi induk tersebarnya jaringan pendirian 43 Madrasah diniyah Takmiliyah di Kecamatan Rancakalong.

\section{Simpulan}

Berdasarkan hasil penelitian terkait Aktivitas K.H. Sholeh Abdul Hafidz dalam Mengembangkan Dakwah Islam di Kecamatan Rancakalong Kabupaten Sumedang Pada Tahun 1957-1987, diperoleh simpulan guna menjawab masalah yang telah dirumuskan. Simpulan tersebut antara lain:

1) K.H. Sholeh Abdul Hafidz atau sering dipanggil dengan Aki Aleh dilahirkan di Kampung Salambitan Desa Cigembong Kecamatan Sumedang Selatan Kabupaten Sumedang pada hari Kamis tanggal 10 Shofar tahun 1345 Hijriyah atau bertepatan pada tahun 1927. K.H. Sholeh Abdul Hafidz merupakan anak keenam dari pasangan Eyang Angga Praja dan Uyut Emeh Salamah. Dan wafat usia 62 tahun pada hari Kamis 2 April 1987 atau bertepatan pada 3 Sya'ban 1407 H pukul 07:00 di Rumah Sakit Umum Cianjur dan dimakamkan di Pondok Pesantren Bunisari I

2) Aktivitas dan Kontribusi K.H. Sholeh Abdul Hafidz dalam mengembangkan dakwah Islam di Kecamatan Rancakalong Pada Tahun 1957-1987 meliputi terdiri dari:

K.H. Sholeh Abdul Hafidz datang ke Rancakalong pada tahun 1957. Hal yang melatarbelakangi kedatangan tersebut adalah kondisi Sumedang terutama di Kampung Sulambitan pada saat tahun-tahun itu yang sedang gencar-gencarnya DI/TII, K.H. Sholeh berada dalam kondisi yang tidak aman pada saat itu, kemudian diajak oleh pendatang dari Rancakalong yang bernama Bapak Ece untuk menggembara di wilayah kecamatan Rancakalong. Langkah awal dakwah yang dilakukan oleh K.H. Sholeh Abdul Hafidz diawali dengan pendekatan dengan golongan muda dari kalangan masyarakat. Kemudian pendekatan kepada golongan tua, dengan 
melakukan silaturahmi terlebih dahulu dengan mengunjungi masjid-masjid kecil yang ada di tiap desa se kecamatan Rancakalong. proses dakwah dibarengi dengan membuka usaha menjahit, sehingga bisa membangun rumah, masjid hingga pesantren. Dalam proses dakwahnya beliau menggunakan tiga metode dakwah yaitu metode Hikmah, metode Mauidzhah Hasanah, dan metode Jadulhum Billatihiya Ahsan. Pendekatan kepemimpinan yang diterapkan oleh K.H. Sholeh Abdul Hafidz dalam mengelola pondok pesantren dan mengembangkan dakwah Islam yaitu pendekatan kepemimpinan yang kharismatik.

Kontribusi dari aktivitas K.H. Sholeh Abdul Hafidz dalam mengembangkan dakwah Islam di Kecamatan Rancakalong pada tahun 1957 masih berjalan hingga sekarang. Perjuangan beliau dilanjutkan oleh anakanak serta menantu-menantu beliau, tidak terkecuali dengan murid-murid beliau. Bentuk kontribusi yang masih terlihat hingga sekarang adalah berdirinya lembaga-lembaga keagamaan di Kecamatan Rancakalong setelah beliau datang, terdiri dari:

1) Pondok Pesantren Bunisari I, Pondok Pesantren Bunisari, Pondok Pesantren Al-Huda dan Pondok Pesanten Al Ulumusyariah.

2) Majelis taklim menjadi salah satu kontribusi yang berkembang pesat dan menyebar di wilayah sekecamatan Rancakalong.

3) Terdapat lima Madrasah Diniyah Takmiliyah yang ditiap desa di kecamatan Rancakalong bahkan ada yang di luar kecamatan sekalipun. Lima Madrasah Diniyah Takmiliyah tersebut menjadi induk tersebarnya jaringan pendirian 43 Madrasah diniyah Takmiliyah di Kecamatan Rancakalong. 


\section{Daftar Sumber}

\section{1) Arsip dan Dokumen}

Catatan Asli K.H. Sholeh Abdul Hafidz Tentang Silsilah Nabi Muhammad S.A.W Tahun 1988

Catatan Asli K.H. Sholeh Abdul Hafidz Tentang Tata Cara Beribadah (Fikih) dan Tajwid

Catatan Asli K.H. Sholeh Abdul Hafidz Tentang Tauhid Tahun 1988

Catatan Asli K.H. Sholeh Abdul Hafidz Tentang Adab Terhadap Orangtua Tahun 1988

Zafar Shidiq, Suluk Abdul Hafidz (Rancaekek:Bandung, 2013)

\section{2) Buku}

Abd Rahman Hamid dan Muhammad Saleh Madjid, Pengantar Ilmu Sejarah. (Yogyakarta:Penerbit Ombak, 2014),43.

Hasan Usman, Metode Penelitian Sejarah, terj. Muin Umar, dkk (Jakarta: Departemen Agama,1986), 79-80.

Drs. Aam Abdillah, M.Ag, Pengantar Ilmu Sejarah (Bandug:CV Pustaka Setia, 2012), 30.

Dr.H. Sulasman, M.Hum, Metodologi Penelitian Sejarah (Bandung:CV Pustaka Setia, 2014), 109.

Louis Gottschalk, Mengerti Sejarah (Jakarta : UI-Press, 2015), 41.

Zamakhsyari Dhofier. Tradisi Pesantren:Studi Pandangan Hidup Kyai dan Visinya Mengenai Masa Depan Indonesia. (Jakarta:LP3ES. 2019). ,93.

\section{3) Jurnal}

Wahyu Irwansyah Tambunan, Gerakan Politik S.M. Kartosoewirjo (DI?TII 1949-1962). Jurnal POLITEIA, Vol 6. No.1. (Medan: Departemen Ilmu Politik Fakultas Ilmu Sosial dan Ilmu Politik Universitas Sumatera Utara, 2014), 33. Diakses Pada Jum'at, 1 Mei 2020 Pukul 14:00.

Guntur Cahaya Kesuma. Pendidikan Karakter Berbasis Kearifan Lokal Adat Sunda"Ngalaksa" Tarawangsa Di Rancakalong Jawa Barat (AlTadzkiyyah:Jurnal Pendidikan Islam, Volume 7. Dosen Fakultas dan Keguruan IAIN Raden Intan Lampung, 2016), 38.

Robby Darwis Nasution, Kyai Sebagai Agen Perubahan Sosial Dan Perdamaian Dalam Masyarakat Tradisional (Artikel, Volume 19 No. 2 Juli, 2017), 182.

Euis Thresnawaty S, Sejarah Kerajaan Sumedang Larang. (Ujungberung Bandung Balai Pelestarian Sejarah dan Nilai Tradisional Bandung Jln.Cinambo No. 136.patanjala Vol. 3, No. 1, Maret 2011), 154-168. 
Sayfa Aulia Achidsti, Jurnal Kebudayaan Islam: Eksistensi dalam Masyarakat. Vol.12,No.2,Juli-Desember (Yogyakarta:Universitas Gadjah Mada), 2014.

\section{4) Skripsi}

Mohammad Hasby Assidik, Peran KH. Muhammad Sudja'i Dalam Dakwah Islam Di Desa Cileunyi Wetan Kecamatan Cileunyi Kabupaten Bandung Tahun 1931-1983. (Bandung: Jurusan Sejarah dan Peradaban Islam Fakultas Adab dan Humaniora Universitas Islam Negeri Sunan Gunung Djati Bandung, 2012.)

\section{5) Sumber Lisan}

Ustadz H. Dadang Ahmad Harumudin (usia \pm 63 Tahun).

Anak ke 1 dari K.H. Sholeh Abdul Hafidz. Wawancara. Sumedang, Ustadz Dodo Dosen Abidarda (usia \pm 51 Tahun).

Anak ke 8 dari K.H. Sholeh Abdul Hafidz. Wawancara. Sumedang,

Senin 20 Januari 2020 pukul 09:00

Ustadzah Een Mulyati, S.Pd (usia \pm 55 Tahun).

Menantu K.H. Sholeh Abdul Hafidz. Wawancara. Sumedang, Sabtu 30 November 2019 pukul18:30

K.H. Abdurrahman (usia \pm 70 Tahun).

Menantu K.H. Sholeh Abdul Hafidz. Wawancara. Sumedang,

Kiai Ahmad Sujani Jaju (usia \pm 66 Tahun).

Menantu K.H. Sholeh Abdul Hafidz. Wawancara. Sumedang, Jum'at

17 Januari 2020 pukul 14:00

Enceng Saca (usia \pm 78 Tahun).

Murid pertama dari K.H. Sholeh Abdul Hafidz. Wawancara.

Sumedang, Senin 27 April 2020 pukul 09:45 